\title{
Is equal access to higher education in South Asia and sub-Saharan Africa achievable by 2030?
}

\author{
Sonia Ilie ${ }^{1} \cdot$ Pauline Rose $^{1}$
}

Published online: 18 August 2016

(C) The Author(s) 2016. This article is published with open access at Springerlink.com

\begin{abstract}
Higher education is back in the spotlight, with post-2015 sustainable development goals emphasising equality of access. In this paper, we highlight the long distance still to travel to achieve the goal of equal access to higher education for all, with a focus on poorer countries which tend to have lower levels of enrolment in higher education. Analysing Demographic and Health Survey data from 35 low- and middle-income countries in sub-Saharan Africa and South Asia, we show wide wealth inequalities in particular, with few if any of the poorest gaining access to higher education in some countries. We further identify that wealth and gender inequalities interact and tend to be wider in countries where levels of higher education are higher. This implies that expansion in access to higher education may predominantly benefit the rich, unless measures are taken to tackle inequalities. We find that that the rates of increase necessary for the attainment of the equal access goal by 2030 are particularly high. They pose a particularly difficult challenge given the access inequalities present from primary and secondary education in a wide majority of countries in our analysis. We therefore suggest that any measures aimed at attaining the goal need to tackle inequalities in access within a system-wide approach, focusing on the level of education at which inequalities initially manifest, alongside higher education.
\end{abstract}

Keywords Higher education - International development · Educational access · Inequality · sub-Saharan Africa · South Asia

Sonia Ilie

isi22@cam.ac.uk

Pauline Rose

pmr43@cam.ac.uk

1 Faculty of Education, University of Cambridge, 184 Hills Road, Cambridge CB2 8PQ, UK 


\section{Introduction}

Following its neglect in the Education for All framework and Millennium Development Goals, the post-2015 Sustainable Development Goals include a specific target on higher education, namely that: "by 2030 ensure equal access for all women and men to affordable quality technical, vocational and tertiary education, including university" (UN 2015). This renewed emphasis on higher education is linked with recent attention to the benefits of higher education to individuals and societies, in ways that are argued to contribute to economic development and poverty reduction (Bloom et al. 2014; Colclough et al. 2009; Fasih et al. 2012; McMahon 2009; Moretti 2004; Oketch, McCowan and Schendel 2014; Teal 2011) and so to support the achievement of other post-2015 global goals.

The recent focus on higher education reinforces commitments made in the 1948 United Nations Universal Declaration of Human Rights which states: "higher education shall be equally accessible to all on the basis of merit" (UN 1948, Art. 26, paragraph 1) and is further supported by the United Nations 1976 International Covenant on Economic, Social and Cultural Rights which makes a similar commitment to equal access to higher education "on the basis of capacity, by every appropriate means, and in particular by the progressive introduction of free education" (UN 1976, Article 13 2c). But, if these rights-based approaches are to be more than aspirational, attention needs to be paid both to fair selection and to availability of places in higher education (McCowan 2015).

Our paper begins by identifying the current situation regarding inequalities in higher education access by wealth and gender across countries in South Asia and sub-Saharan Africa, which are furthest from achieving the new goal, drawing on recent data from Demographic and Health Surveys in 35 countries. Drawing on these findings, our analysis identifies an immense challenge in achieving equal access to higher education by 2030 in these countries, particularly if equality is anticipated for the poorest young women.

In some of the countries, very few, if any, young people from poor households reach higher education. Wealth gaps are further reinforced by gender gaps, such that the poorest young women are least likely to enter higher education. In those countries where access to higher education has expanded, gaps in access between the rich and poor, and between young women and men, are particularly wide_-implying that expansion has primarily benefited the elite. Our analysis further identifies that wide inequalities in higher education reflect inequalities in primary and secondary schooling. As such, unless inequalities earlier in the educational system are addressed, the higher education target included in the global goals is unlikely to be achieved.

\section{Existing evidence on patterns of access to higher education}

Increased access to higher education has given rise to questions about who has benefited from this expansion, and whether such growth has been equitable. By equity, we follow McCowan's (2007, p. 582) definition that "there must be sufficient places so that all members of society who so desire, and who have a minimum level of preparation, can participate in higher education". McCowan further identifies that achieving equity would mean that all those who meet the first criterion would have a fair chance of accessing institutions of their choice, such that certain groups or individuals are not constrained to lower-quality institutions. This second criterion is important, but more difficult to identify with available cross-national data.

Recent years have seen the rapid expansion of higher education in a number of high-income countries (Schofer and Meyer 2005; Marginson and Van der Wende 2007; Keeling 2006). According to Trow $(1973,2007)$, these systems have grown from an 'elite access phase' to a 
'mass access phase', and, more recently, to a 'universal access phase'. However, massification has not generally led to equitable access, with those from more disadvantaged backgrounds still less likely to be prepared for higher education, meaning that in some countries even if they have the chance to enter, they have a lower chance of completing (Altbach et al. 2009). Some of the inequality in access to higher education in countries such as England, where the system has expanded, is due to inequalities in attainment in primary and secondary schooling (Jerrim and Vignoles 2015).

\section{Focus on sub-Saharan Africa and South Asia}

Much of the research on higher education expansion and equity has focused on middle- and high-income countries, which generally display patterns that place them closer to a 'mass' or 'universal phase' of higher education. By contrast, there is more limited research investigating how access to higher education varies across and within low- and lower-middle-income countries. From the evidence that is available, it is apparent that there have been developments in access in these countries, although most are still in the 'elite access phase', and growth has not been equitable (Carnoy et al. 2013; Salmi and Bassett 2014; UNESCO Institute for Statistics 2014; Chien and Montjourides 2016). As a result, Salmi and Bassett (2014) call for "equity promotion policies to increase opportunities for disadvantaged students are those that combine financial assistance with measures to overcome non-financial obstacles" (p. 365).

In light of this evidence, we have chosen to focus our analysis on countries in South Asia and sub-Saharan Africa, for two main reasons. Firstly, a large proportion of the world's poorest reside in these regions (Sumner 2012), so the regions are a relevant focus given our aim is to explore the patterns of higher education access for the most disadvantaged, and in areas that currently are furthest from achieving sustainable development targets associated with on equitable higher education access. Secondly, many (though not all) of the countries in these regions exhibit particularly wide school enrolment and learning gaps at primary and secondary school levels, providing the opportunity to understand how inequality in schooling potentially affects inequality in higher education access in these parts of the world. Additionally, evidence suggests that enduring gender gaps in education negatively affect these region's economic growth, therefore warranting further empirical investigation (Klasen and Lamanna 2009). There are restrictions on the countries we are able to include in the analysis due to lack of recent data. For South Asia, several large countries are not part of our analysis for this reason: India and Afghanistan; and the smaller states of Sri Lanka and Bhutan are also missing. For sub-Saharan Africa, we include 32 of the 46 developing countries (World Bank 2016) in the region. Given that we do not have data on all countries, our upcoming analysis does not make claims about the entirety of either of these two regions and instead focuses on the overall patterns of higher education access in the countries in our analysis.

In many of the countries in South Asia and sub-Saharan Africa, the growth in enrolment has placed a strain on public higher education institutions, with financial resources to state institutions not growing at the same pace as enrolment. This is leading to a growth in private institutions in response to increased demand for places in some contexts (Teferra and Altbachl 2004; Jamshidi et al. 2012). This rise in private provision may pose challenges to the mitigation of existing inequalities via differences in the type and quality of private higher education provision that different population groups can access (e.g. Susanti 2011; Tilak 2014). Moreover, even the recent growth of private higher education institutions is unlikely to close the gap in enrolment with more developed countries. In our analyses, we do not assess the supply-side of the higher education sector when discussing 
Table 1 Summary of key higher education metrics used by different international bodies Sources: OECD (2014, 2015); UNESCO Institute for Statistics $(2009,2015)$

\begin{tabular}{|c|c|c|c|}
\hline \multirow{2}{*}{$\begin{array}{l}\text { Overarching } \\
\text { metric }\end{array}$} & \multicolumn{3}{|l|}{ Definition of metric } \\
\hline & $\begin{array}{l}\text { UNESCO Institute for } \\
\text { Statistics }\end{array}$ & OECD & DHS (this paper) \\
\hline $\begin{array}{l}\text { Net enrolment } \\
\text { rate/net } \\
\text { attendance } \\
\text { rate* }\end{array}$ & $\begin{array}{l}\text { Number of HE-age students } \\
\text { (5-year age group starting } \\
\text { from the official } \\
\text { secondary school } \\
\text { graduation age) who are } \\
\text { enrolled in HE }\end{array}$ & $\begin{array}{l}\text { Number of persons aged } \\
20-24 \text { enrolled in tertiary- } \\
\text { level education. Overall } \\
\text { size of the } 20-24 \text { age } \\
\text { group allows for } \\
\text { calculation of net } \\
\text { enrolment rate }\end{array}$ & $\begin{array}{l}\text { Number of students of } \\
\text { higher education age } \\
\text { (starting from the official } \\
\text { end of secondary school } \\
\text { to 24) enrolled in any } \\
\text { form of higher education, } \\
\text { as a proportion of the } \\
\text { same-age group }\end{array}$ \\
\hline $\begin{array}{l}\text { Gross } \\
\text { enrolment } \\
\text { rate/gross } \\
\text { attendance } \\
\text { rate }\end{array}$ & $\begin{array}{l}\text { Number of any-age students } \\
\text { who are enrolled in HE, } \\
\text { as a proportion of HE-age } \\
\text { students (5-year age } \\
\text { group starting from the } \\
\text { official secondary school } \\
\text { graduation age) }\end{array}$ & $\begin{array}{l}\text { Number of persons of all } \\
\text { ages enrolled in tertiary- } \\
\text { level education. Also } \\
\text { available for age groups } \\
25-29 ; 30-34 ; 35-39 . \\
\text { Overall size of all age } \\
\text { groups allows for } \\
\text { calculation of gross } \\
\text { enrolment rates }\end{array}$ & $\begin{array}{l}\text { Data not available: HE } \\
\text { attendance question not } \\
\text { asked of respondents over } \\
\text { the age of } 24 \text { years in } \\
\text { most countries }\end{array}$ \\
\hline $\begin{array}{l}\text { Net attainment } \\
\text { rate }\end{array}$ & $\begin{array}{l}\text { Number of adults (aged } 25 \\
\text { and over) who have } \\
\text { attained higher education, } \\
\text { as a proportion of the } \\
\text { respective age group }\end{array}$ & $\begin{array}{l}\text { Number of adults who have } \\
\text { completed higher } \\
\text { education of a given age } \\
\text { group (25-34; 25-64; } \\
\text { 55-64), expressed as a } \\
\text { proportion of the } \\
\text { respective age group }\end{array}$ & $\begin{array}{l}\text { Net participation rate: } \\
\text { Number of persons in } \\
\text { particular age groups who } \\
\text { have ever attended higher } \\
\text { education, as a proportion } \\
\text { of the total numbers in the } \\
\text { respective age group }\end{array}$ \\
\hline $\begin{array}{l}\text { Gross } \\
\text { attainment } \\
\text { rate }\end{array}$ & $\begin{array}{l}\text { Gross graduation ratio: } \\
\text { Number of students } \\
\text { graduating from a first } \\
\text { degree, as a proportion of } \\
\text { persons of the theoretical } \\
\text { age at graduation (given } \\
\text { by the graduation age of } \\
\text { the mode HE program) }\end{array}$ & $\begin{array}{l}\text { Percentage of adults who } \\
\text { have attained tertiary } \\
\text { education, by the type of } \\
\text { programme and age group } \\
\text { (2012) }\end{array}$ & $\begin{array}{l}\text { Gross participation rate: } \\
\text { Number of persons ever } \\
\text { having attended higher } \\
\text { education, regardless of } \\
\text { age, as a proportion of the } \\
\text { HE-age population as } \\
\text { defined above }\end{array}$ \\
\hline Disaggregation: & Gender & Gender & Gender and wealth \\
\hline
\end{tabular}

Italics indicates an alternative, but similar version of the indicator used when the initial indicator is not used, or data are not available

*The terminology of enrolment and attendance rates arises from the source of data: enrolment rates are based on administrative data; attendance rates are based on survey data

the opportunities for access different population groups, but note that further systematic research that explores these issues is required.

\section{International data: source for understanding patterns of higher education access}

Data from the UNESCO Institute for Statistics show that despite some expansion, access to higher education in low-income countries still lags far behind other parts of the world. 


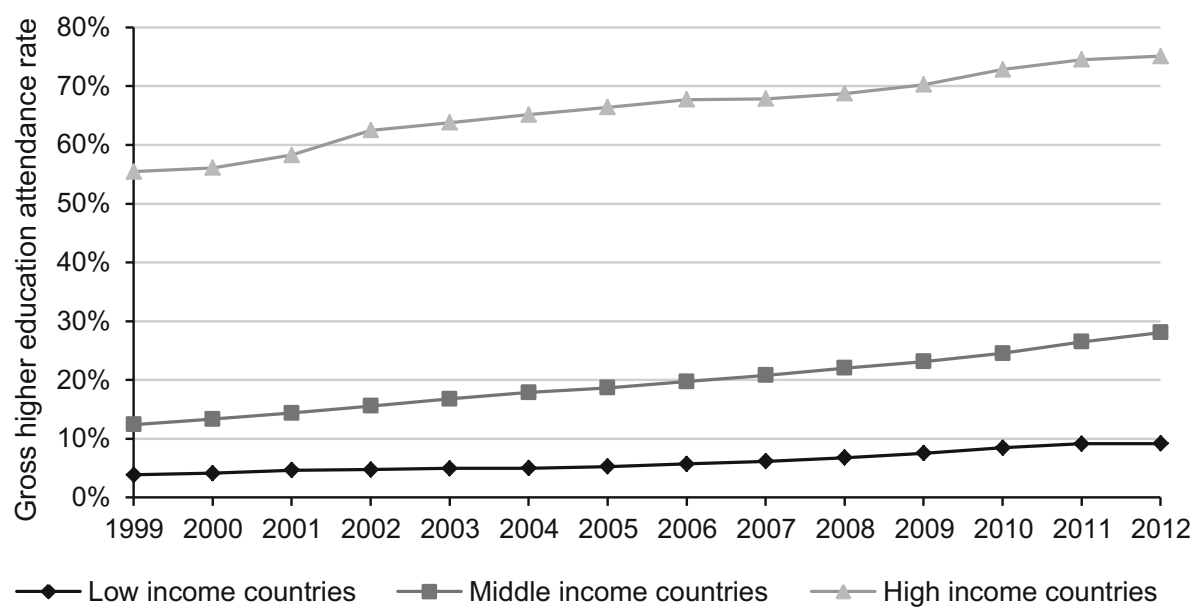

Fig. 1 Higher education gross enrolment rates, by country income group, over time. Source: Authors' calculations based on UNESCO-UIS (2015) data

By 2012, higher education gross enrolment rates $^{1}$ in low-income countries were approximately $10 \%$, barely reaching the level of middle-income countries in 1999. And, by 2012, both low- and middle-income countries were far below the level achieved in high-income countries (Fig. 1). By contrast, not only is enrolment significantly higher in high-income countries, but the gross enrolment rate for high-income countries increased substantially between 1999 and 2012, by approximately 20 percentage points. By contrast, access to higher education has increased from a very low base in sub-Saharan Africa and South Asia over the past 15 years. In sub-Saharan Africa, progress has been slow, with only $4 \%$ of young people gained access in 1999, at the outset of the Millennium Development Goals, increasing to just $8 \%$ by 2012. Progress has been faster in South Asia, increasing from 8 to $23 \%$ over this period (UNESCO Institute for Statistics database 2015).

Data from the UNESCO Institute for Statistics are important for illustrating overall patterns in access, including by gender. Globally, young women are more likely to attend higher education than young men. However, in South Asia and sub-Saharan Africa this pattern is reversed: 81 young women are enrolled for every 100 young men in South Asia, with a ratio of 64 young women to 100 young men in sub-Saharan Africa (UNESCO Institute for Statistics 2015). These data are, however, unable to provide patterns on other dimensions of inequality, notably according to wealth status. Household surveys, such as internationally comparable Demographic and Health Surveys, provide the opportunity for such an assessment. In this paper, we draw on these latter data to assess the distance still to travel to achieve a goal aiming for equality in access to higher education by 2030, with a focus on poorer countries in South Asia and sub-Saharan Africa which, according to UNESCO Institute for Statistics (2015), tend to have lower levels of enrolment in higher education, and wide gender gaps at the expense of young women.

Ideally, post-2015 targets should track progress towards access to higher education that is good quality and relevant to the demands of the labour market. However, data on quality

\footnotetext{
${ }^{1}$ See Table 1 for the UNESCO Institute for Statistics calculation for gross enrolment rates.
} 
and relevance are even less readily available than data on access to higher education. Future work must therefore explore the kinds of institutions, programmes and courses to which different social groups gain access, connecting their trajectories with labour market and other economic social outcomes, so that we may understand the composite effects higher education can have on people's lives. Such evidence would need to be assessed within particular national contexts, taking account of the wide variation in starting points for higher education access, as well as diversity in labour markets and other social conditions across countries.

\section{Data and methods}

The primary focus of our research is to identify patterns in access to higher education by wealth and gender. We further explore the link between inequalities at this level and gaps in access in primary and secondary education, as a means to understand the likely challenges of achieving equal access to higher education by 2030. To address this, we make use of the Demographic and Health Surveys (DHS 1988-2015), which are large-scale, nationally representative surveys, and allow for comparisons across countries. We focus on countries in South Asia and sub-Saharan Africa with DHS surveys carried out between 2007 and 2014. Within these surveys, several questions are asked of participants about educational attendance, which are relevant to our analysis. As a first step, we have to select appropriate indicators for assessing patterns in access to higher education. This is necessary due to a current lack of international consensus about which indicators should be used to monitor progress towards the 2030 goals, which is of relevance to our analysis. We therefore first present the set of potentially appropriate higher education indicators used in the wider literature and available in international databases, as a means to selecting ones that are feasible and appropriate to our analysis using data from the Demographic and Health Surveys.

\section{Identifying indicators for measuring progress towards 2030 higher education target}

Monitoring progress towards the post-2015 target of equal access to higher education requires high-quality data disaggregated for different population groups that will allow for a baseline to be established and, subsequently, for progress to be measured against that baseline. The identification of a suitable indicator is not straightforward, due to limitations in the availability of appropriately disaggregated data, as well as some of the challenges of measuring higher education access. The choice between indicators reporting on either net or gross rates reveals different underlying foci: while net attendance rates reflect the proportion of young people (including recent graduates of secondary education) who progress into higher education, gross rates capture the wider scale of the higher education system and allow for the inclusion of those with nonlinear education trajectories. However, the gross rate focuses on this wider group relative to a narrower age group (usually below the age of 25) and so presents an inflated figure which could even be over $100 \%$. And neither of these indicators provides evidence as to the success of those initially enrolled: only graduation and completion rates do so, but the increasing diversity in type and length of higher education qualifications renders them difficult to compile and compare. 
The education Technical Advisory Group (2015) on post-2015 indicators proposes using the gross enrolment ratio for tertiary education, based on the approach of the UNESCO Institute for Statistics (see Table 1). While gross rates may serve to compare the absolute participation in different types of higher education programmes, limitations arise due to the diversity in programmes' duration, in the ages of first enrolment and in the increasing variety of types and levels of higher education provision (UNESCO Institute for Statistics 2014).

Further, the precise approach towards measuring internationally comparable gross enrolment ratios varies between OECD and UNESCO Institute for Statistics key sources. One of the key differences is the choice of age range for the higher education population; however, this is unlikely to make a significant difference. What is more likely to make a difference is the choice of gross or net indicators-i.e. whether only those within the identified age group are included or whether the indicator measures everyone, regardless of age, as a proportion of the identified age group. In countries where it is more common for mature students to be enrolled on courses, this could inflate the gross enrolment relative to the net one.

UNESCO Institute for Statistics and OECD break down higher education enrolment figures by gender. They also provide information on the type of higher education programme $^{2}$ and by subject, although there are significant data gaps for these indicators, particularly noticeable for poorer countries. We present the key higher education metrics used by UNESCO Institute for Statistics, the OECD, alongside those adopted in our paper (using DHS data) in Table 1. Other indicators referencing higher education exist; however, here we focus only on those that are similar in their meaning and construction.

\section{Methods for analysis}

Given that OECD and UNESCO data on higher education access do not allow disaggregation of data by wealth status, we use nationally representative DHS data for this purpose. We use the most recent round of DHS data available in countries in South Asia and subSaharan Africa, including those with surveys between 2007 and 2014, resulting in a total of 35 countries. While this does not represent a complete list of all the countries in the two regions of interest, they include a sufficient number of nations to warrant wider conclusions about the regions as a whole. Our results are based on weighted DHS data and therefore can be considered, within the limits noted by each individual country survey, representative of the higher education situation at the time of the survey in each respective country. DHS instruments include a common core of questions, including two main approaches to collecting information from which access to higher education can be obtained: first, by asking about current education attendance of household members aged 24 and under; and second, by asking all household members about the highest level of education already attained. Neither of these questions distinguishes between the level (undergraduate or postgraduate) or type (university, college, technical institution, etc.) of higher education attended. While we recognize that access to different kinds of higher education provision may be differently distributed in the populations of interest, data limitations mean that the enrolment rates we report aggregates information on access to any of these different kinds of provision.

Drawing on the approaches used by OECD and UNESCO, we calculate a net attendance rate using information on current attendance for the age group immediately following the

\footnotetext{
${ }^{2}$ Using the ISCED 2011 classification (UNESCO Institute for Statistics 2011): ISCED 5: short-term tertiary programmes; ISCED 6: Bachelor's programmes or equivalents; ISCED 7: Master's level programmes or equivalents; and ISCED 8: doctoral programmes or equivalents.
} 
official secondary school graduation age until age 24 inclusively (as 24 is the cut-off age for which information on current attendance is available from DHS, which also covers the length of most undergraduate programmes). For the majority of countries, the starting age for higher education is, therefore, 18 or 19 years and varies between 17 and 20 years overall. ${ }^{3}$

However, it is not possible to calculate a gross attendance rate given that DHS data do not provide information on current attendance for those over 24 years. As an alternative, we calculate an indicator of participation based on the highest level of education ever attended using DHS data. This allows us to include those who are older than 24 years.

For our main analysis, which is concerned with progress towards the post-2015 Sustainable Development Goals, we focus on higher education enrolment for the age-appropriate group (similar to the indicator used for primary education in the Millennium Development Goals). This is because including all adults, regardless of age, as a proportion of a more limited higher education age group, inflates the ratio. Using the net attendance indicator allows us to place emphasis on the age group which is most likely to be continuing directly from secondary school and subsequently to be making their first transition from higher education into the labour market - and so contributing to the country's economic growth and poverty reduction goals.

The advantage of the DHS data is that they allow for an analysis of higher education access levels by wealth groups. To calculate these, we use the DHS-derived wealth index (Rutstein and Johnson 2004). This is a composite index that accounts for the household possessions of survey respondents, is comparable across countries, and is routinely used in estimating deprivationdriven inequalities as a proxy for income (Filmer and Pritchett 2001; Traynor and Raykov 2013). Using this index allows us to split the households in the sample into different wealth groups. Using wealth quintiles, as customary in analyses related to wealth differences, proved impractical for our purposes since higher education attendance amongst the most-deprived two quintiles was extremely close to zero and exhibited limited between-country variance. We therefore chose to focus on the median as the cut-off point and investigate differences between the poorest $50 \%$ and the richest $50 \%$ of each respective country's population.

\section{Limitations of our approach}

Our approach allows for the exploration of net rates of higher education access for different wealth groups in each country, and patterns across countries selected for the analysis. It does not allow us, however, to make any inferences about the direct causes of the observed inequalities. Indeed, as we have already discussed, we cannot factor in the size of national higher education sectors, nor can we include evidence of the particular circumstances of each country's political and economic situation. We recognize that these issues are likely to have an impact on the opportunities for higher education access: factors such as political instability or rapid economic growth, onset of conflict or transition to peace, public health crises, or natural disasters can all translate into variation in both the provision of higher education, and the chances of different population groups to access existing provision.

Given data availability, our analysis only captures information collected from households at one point in time: since we use DHS data from 2007 onwards (which we deem

\footnotetext{
3 The official secondary graduation ages are: 16 in Nepal, Sao Tome and Principe, and Pakistan; 17 in Bangladesh, Democratic Republic of Congo, Gabon, Kenya, Lesotho, Liberia, Madagascar, Malawi, Maldives, Mozambique, Nigeria, Sierra Leone, and Swaziland; 18 in Benin, Burkina Faso, Cameroon, Comoros, Congo, Cote d'Ivoire, Ethiopia, Ghana, Mali, Namibia, Rwanda, Zambia, and Zimbabwe; and 19 in Guinea, Niger, Senegal, Tanzania, and Togo.
} 


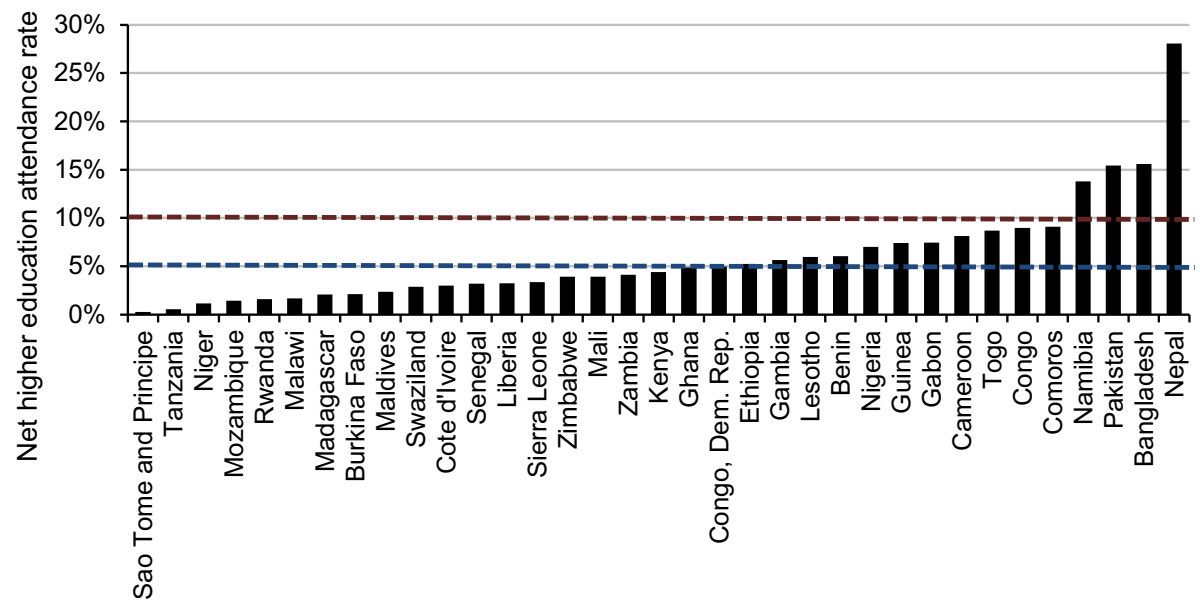

Fig. 2 Higher education net attendance rate, young persons under the age of 25, by country. Source: Authors' calculations based on Demographic and Health Survey data

temporally close enough to warrant comparisons), we may not capture extremely recent growth that may have occurred in some countries. In Nigeria, for instance, internationally collated administrative data suggest there is a relatively large higher education sector compared to other countries in sub-Saharan Africa (UNESCO-UIS 2015). However, national evidence points to very strong fluctuations in access rates over time (Aluede et al. 2012; Ogunmuyiwa and Okuneye 2015).

Despite these limitations, our analysis provides crucial information regarding inequalities in higher education access required for the monitoring of progress towards the Sustainable Development Goals. By investigating the links to wealth- and gender-driven access gaps at primary and secondary school alongside those in higher education, we develop a broader picture of inequalities, highlighting the need to look at education inequalities across the system, rather than for individual levels within the system, if progress towards a target of equal access to education at all levels is to be achieved.

\section{Results}

\section{Higher education access levels: consistently low}

Across the 35 South Asian and sub-Saharan African countries included in our analysis, we find that access to higher education for young people under the age of 25 is extremely low in almost all of the countries. It is below $10 \%$ in 31 countries, and below $5 \%$ in 20 of these. Higher education net attendance rates are generally lower in sub-Saharan African compared with South Asian countries, with no more than $2 \%$ of young people enrolled, on average, in countries such as Malawi, Mozambique, Niger, Rwanda, Sao Tome and Principe, and Tanzania. The three African countries with the highest rates are Namibia (14\%), and Comoros Islands and Congo (both at $9 \%$ ). Still modest, higher education net attendance rates exceed these in Pakistan (15\%), Bangladesh (16\%), and Nepal (28\%) (Fig. 2). ${ }^{4}$

\footnotetext{
${ }^{4}$ Not surprisingly, we find that the gross participation rate (calculated as the proportion of adults of any age who have ever attended higher education) is much higher than the net attendance rate for many countries. In Bangladesh, for instance, the net attendance rate is $15 \%$, while the gross participation rate is $60 \%$. In
} 


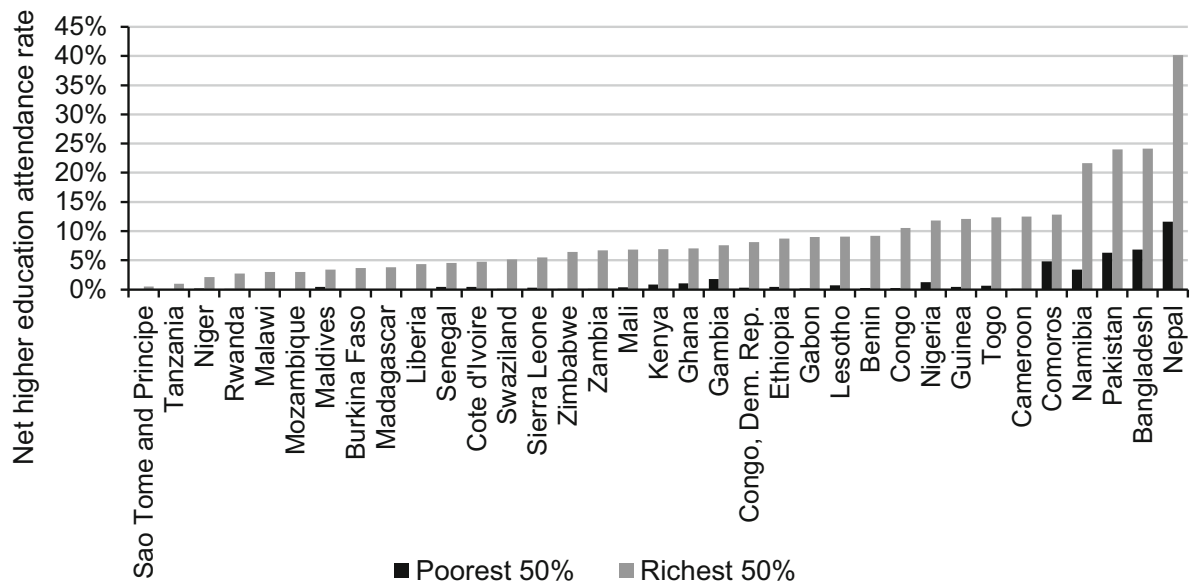

Fig. 3 Higher education net attendance rates, young persons under the age of 25, by wealth. Source: Authors' calculations based on Demographic and Health Survey data

\section{Higher education access wealth-related inequalities: wide gaps}

Average attendance rates mask vast differences between population groups within countries. Comparing net attendance rates between the poorest and the richest in each country (based on the DHS wealth index, as described above), we find that there are five countries where the number of poor young person under the age of 25 gaining access to higher education is not statistically different from zero: Burkina Faso, Liberia, Malawi, Sao Tome and Principe, and Tanzania (Fig. 3). Not surprisingly, these are countries where enrolment overall is low, and so the corresponding rates for the richest half of the population in these countries are also small (3.7 \% in Burkina Faso, $4.4 \%$ in Liberia, $3 \%$ in Malawi, $0.5 \%$ in Sao Tome and Principe, and $1 \%$ in Tanzania).

In addition, we find that only four of the 35 countries (Comoros and Bangladesh, Nepal and Pakistan) display a pattern whereby more than $5 \%$ of the poorest half of young people gain access to higher education. Even in these countries, a rich young person is 3-5 times more likely to attend higher education than a poor young person.

\section{Higher education access gender inequalities: young women at a slight disadvantage}

Gender-driven differences in access, which are found to be in favour of young men in South Asia and sub-Saharan Africa using data from the UNESCO Institute for Statistics, are also identified in our analysis. Across the 35 countries, young men under the age of 25 are, on average, more likely to gain access to higher education than young women in the same-age group (Fig. 4). In countries where young women would appear to enter higher

Footnote 4 continued

Nepal, the gap between net and gross rates is around 11 percentage points, possibly indicating recent growth in enrolment. However, the gross participation rate is low for many sub-Saharan African countries signalling that few amongst the older age groups have had access to higher education: the gross rate is below $10 \%$ in seven of the 35 countries, and below $20 \%$ in 12 countries. 


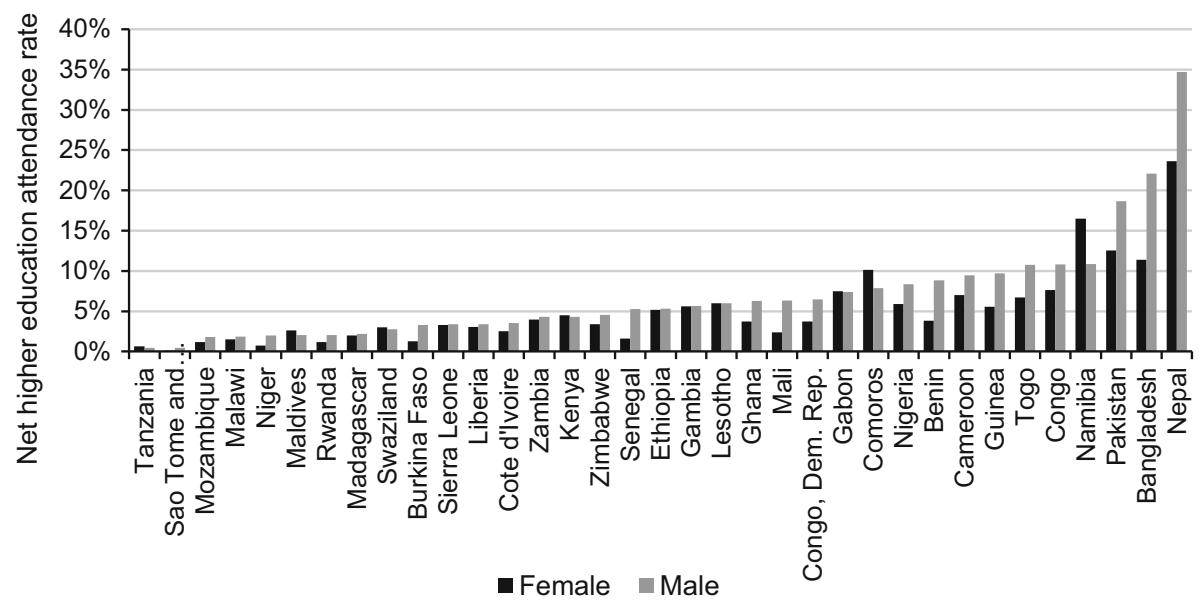

Fig. 4 Higher education net attendance rates, young persons under the age of 25, by gender. Source: Authors' calculations based on Demographic and Health Survey data

education in larger proportions than men (in just seven of the 35 countries: Comoros, Gabon, Kenya, Maldives, Namibia, Swaziland and Tanzania), the gender-based access differences are not statistically significant, except for Namibia, where women are statistically more likely to access higher education than men.

Where access is restricted to a very small proportion of the under-25 population overall, the proportions of both young men and women enrolled in higher education are similarly very low. In these countries, it is likely to be only the richest, whether male or female, who have any chance of gaining access. However, countries that exhibit higher levels of overall higher education access also display larger gender gaps in favour of young men. In Nepal, for example, $24 \%$ of women under the age of 25 attend higher education compared with $35 \%$ of young men. Namibia is the exception amongst the group of countries in our analysis, being the only one where young women are significantly more likely to attend higher education.

\section{Gender and poverty barriers to access: poorest youngest women chronically underrepresented}

The general pattern of access by gender would imply that, as poorer young people start to have the opportunity to attend higher education, they are likely to be disproportionately male. This is confirmed by the next stage of our analysis, which looks at the interaction between wealth and gender (Fig. 5). In 24 of the 30 countries where at least some of the poorest are enrolled, poorest young women are least likely to be in higher education. In 15 of these countries, the richest young men are most likely to be enrolled; in the majority of the other countries, the difference to the benefit of women is marginal, with the exception of Comoros and Namibia. In some of the higher enrolment countries, the gap between poor young women and poor young men is particularly stark. In Guinea, for example, less than $0.1 \%$ of poor young women are enrolled compared with $1.1 \%$ of poor young men and $15 \%$ of rich young men. Similarly, in Nigeria, the net attendance rate for poor young women is just $0.4 \%$ compared with $13 \%$ for young rich males. 


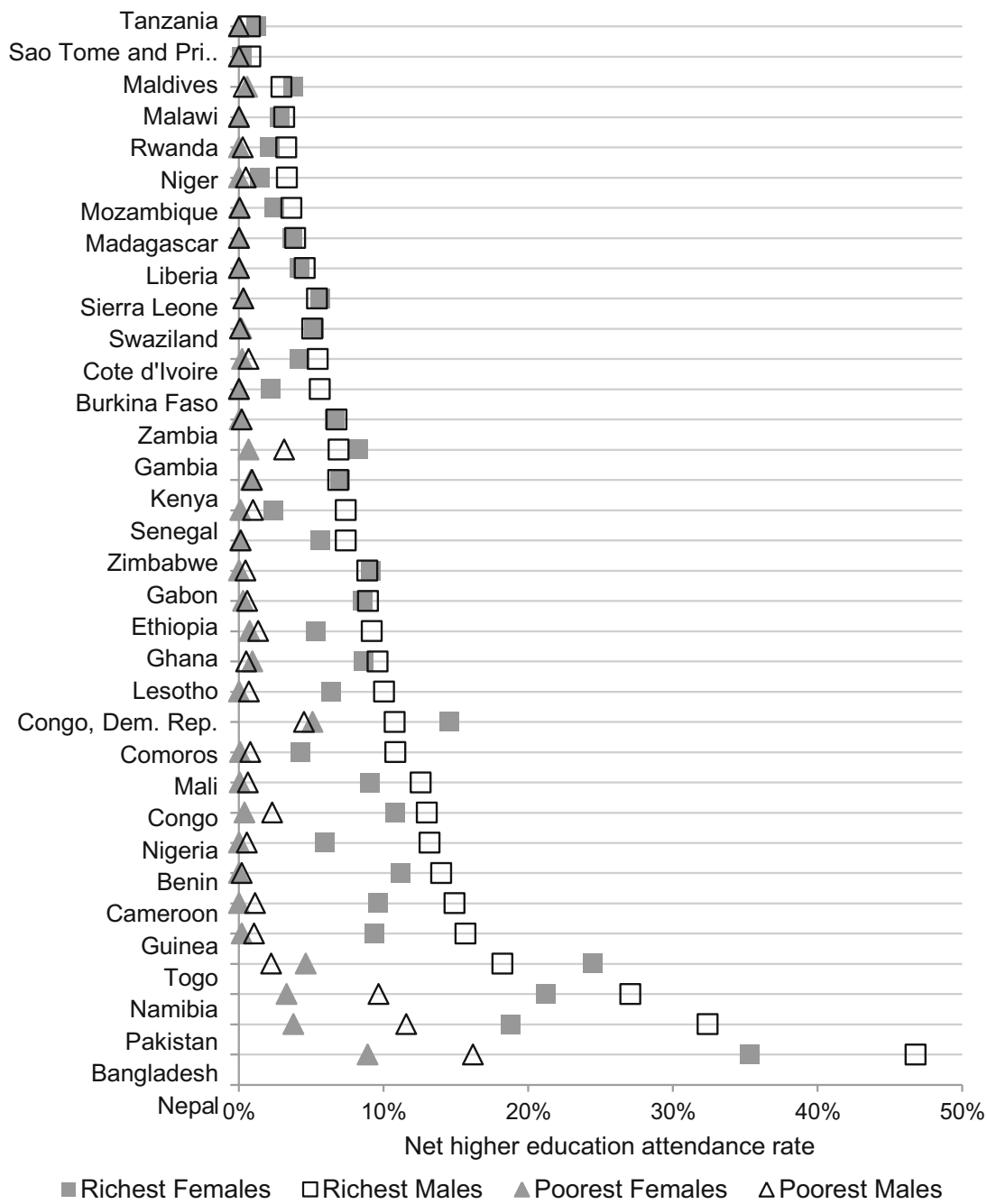

Fig. 5 Higher education net attendance rates for young persons under the age of 25, by wealth and gender. Source: Authors' calculations based on Demographic and Health Survey data

As overall access to higher education expands, the challenge is to ensure that growth occurs equitably. In Bangladesh, for example, rich young men are approximately 10 times more likely to attend higher education than poor young females; the net attendance rate in the country is $33 \%$ for rich young males, but only $4 \%$ for poor women.

While gender inequality continues to be a cause for concern, the magnitude of gender gaps is smaller than that of wealth-driven gaps. However, given that countries with higher rates of higher education participation also tend to have wider gender gaps amongst both the rich and the poor, there is a danger that, as higher education systems expand in countries with lower levels of access, so could the gender gaps. This suggests the need to put in place strategies to address gender and wealth inequalities early on. As such, where 
higher education attendance rates are overall very small, the focus should be on measured expansion that is pro-poor and tackles any gender imbalance from the very beginning.

\section{Is a target of equal access to higher education by 2030 attainable?}

Wide inequalities in access to higher education that we have identified for some of the world's poorest countries suggest that the achievement of a target of equal access by 2030 could be a distant dream. To assess the potential for countries in South Asia and subSaharan Africa to achieve such a target under current conditions, we estimate the progress that the countries have made in the recent past, and compare this with progress that will be needed over the next 15 years. Given wealth gaps predominate, we focus on these. We recognise that the current phrasing of the post-2015 target focuses on equal access for all men and women; however, we argue that this can only be achieved if wealth gaps are narrowed given these drive gender gaps.

To estimate past trends in the absence of real longitudinal data (which the design of the DHS survey does not provide), we make use of the fact that we can estimate net participation rates for progressively older cohorts using the cross-sectional survey data. We take a retrospective cohort analysis approach, by calculating net participation rates using information on the highest attended educational level for every 5-year age group following from the under-25 category: for instance, for the group aged 35-39 at the time of the survey, we calculate the net participation rate as the number of persons aged 35-59 who have ever attended higher education divided by the overall number of 35-39 year-olds in the sample. ${ }^{5}$

We present the trends by highlighting the median year in which each of these cohorts will have potentially started higher education, given the time span over which the DHS surveys we draw on were conducted, and separately for the richest and poorest in each country (Figs. 6, 7). This provides a modest example of progress that is needed to narrow gaps (a focus on the bottom and top quintiles would result in an even more divergent situation).

The overall trend for the poorest groups across all sample countries is one of stagnation, with only a small number of points of growth: in the group aged 50-54 at the time of the survey (an age at which respondents could potentially have been enrolled in higher education around 1975), fewer than $2 \%$ of the poorest were enrolled in higher education in any of the 35 sample countries; for the group aged 35-39 at the time of the survey (around 1990) the rate rises above $2 \%$ in only 3 countries (Bangladesh, Gambia and Pakistan), but remains below $5 \%$ in all of these. Any increase in participation for the poorest group only comes most recently, and even then the improvements are marginal: for the cohort aged 25-29 (median year of potential access: 2000), only Comoros exhibits a net participation rate above $5 \%$.

For the richest groups, many countries show limited growth of access to higher education, although at a slightly better rate of growth than the poorest groups above. In a majority of countries ( 22 out of 35 ), the growth between the oldest and the youngest age

\footnotetext{
5 Net attendance and net participation rates differ, on average, only slightly. For the poorest under 25 years, the differences between net participation and net attendance rates are less than 1 percentage point in all countries except Pakistan, Nepal, and the Maldives. For the richest under 25 years, the differences are slightly higher: twelve countries exhibit differences of under 1 percentage point for the two rates (such as Niger and Gabon), a further nineteen countries show differences between net participation and net attendance rates of under 5 percentage points (such as Liberia or Malawi), and the remaining 4 countries (Bangladesh, Ethiopia, Nepal, and Pakistan) display larger differences.
} 


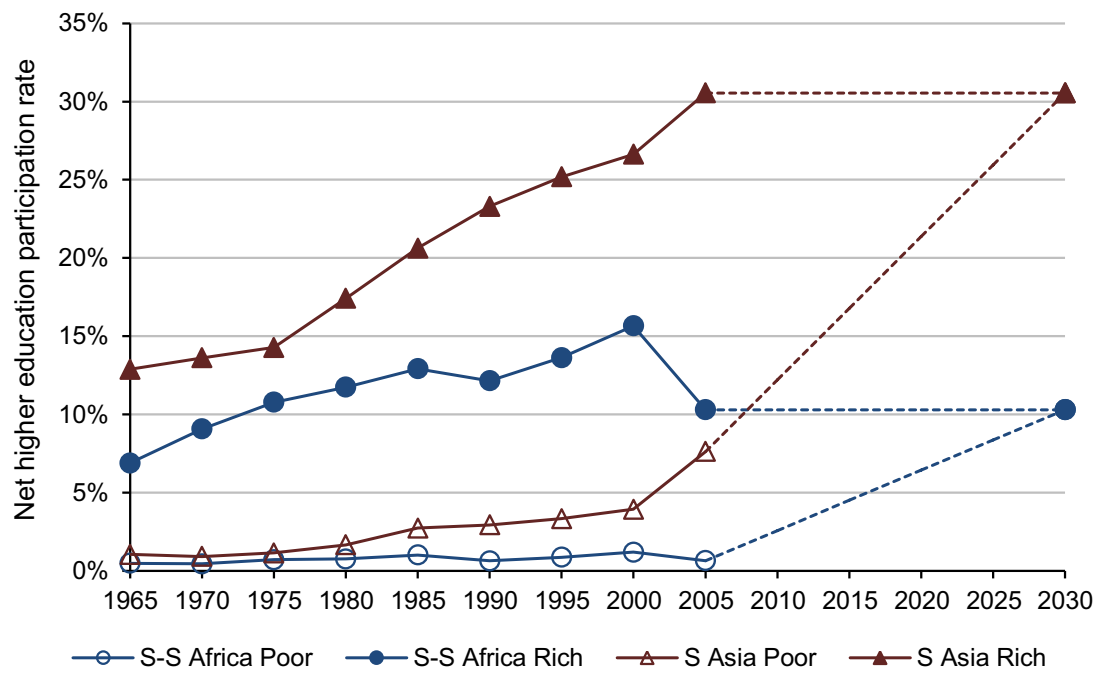

Fig. 6 Higher education net participation rates, poorest and richest $50 \%$ of each country, by region and mean potential year of higher education access; Scenario 1: dotted lines represent simulated growth necessary for the poorest to reach current levels attained by the richest in each region. Source: Authors' calculations based on Demographic and Health Survey data

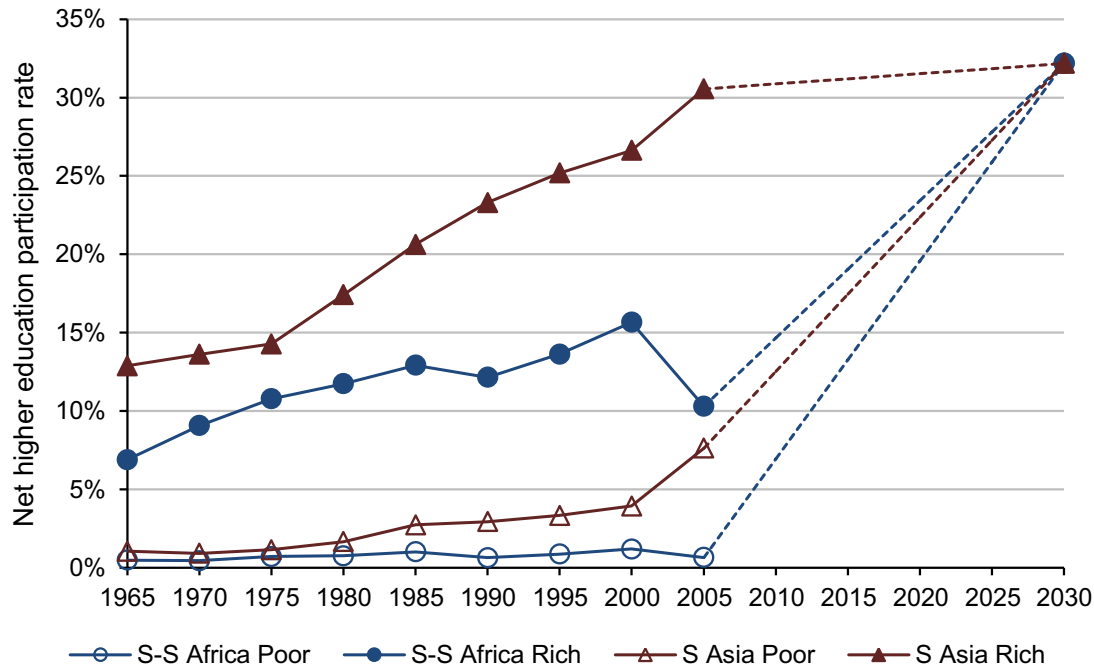

Fig. 7 Higher education net participation rates, the poorest and richest $50 \%$ of each country, by region and mean potential year of HE access; Scenario 2: dotted lines represent simulated growth necessary to attain access equal to the highest level currently attained by the richest group in the highest performing country. Source: Authors' calculations based on Demographic and Health Survey data

groups is less than 5 percentage points. For the remainder of thirteen countries, there is a stronger upward trend for the richest, such that the youngest rich cohorts in countries like Bangladesh, Nepal or Nigeria are at least 10 percentage points more likely to access higher education that the oldest rich cohorts. 
These trends indicate the gap in higher education participation of poor and rich has, if anything, widened over time, as the rich have mostly been the beneficiaries of any expansion that has occurred in higher education provision. If these trends continue, the potential to attain a goal of equality of access in higher education by 2030 seems remote.

To illustrate the distance to travel to achieve equality of access and participation in South Asia and sub-Saharan Africa, we assume two potential scenarios. ${ }^{6}$ First, we assume the rates for the poorest increase so that, by 2030, they reach current levels for the richest (Fig. 6). This is a very conservative estimate, as the expectation is that the richest groups in many of our sample countries will experience some increase of higher education access, which certainly should not be constrained. We, therefore, plot a second scenario which assumes that the net participation rate increases for both the poorest and richest groups across all countries to reach the highest rate currently observed for the rich group in any of the countries (namely Pakistan, where $32 \%$ of the richest half of under 25-years have ever attended higher education) (Fig. 7). ${ }^{7}$ We also recognize that these two scenarios are, inevitably, only indicative. There could be many more permutations, depending on the extent of expansion in higher education that is envisaged in different countries. We also assume simple linear increases from the most recent year to $2030 .^{8}$

Our most modest scenario assumes that by 2030 the poorest persons will catch up with the levels exhibited by the richest at the time of the survey (Fig. 6). Even this scenario is ambitious in South Asia, where the rich have fared better, most recently reaching around $30 \%$ net participation rate, on average. Here, participation of the poor will have to increase by approximately 4.5 percentage points every 5 years after 2005 , compared to an average rate of increase of 0.9 percentage points every 5 years for the period starting 1965 . In sub-Saharan Africa, the increase in participation for the poorest to reach a target of $10 \%$ achieved by the richest ${ }^{9}$ would occur from a baseline where participation for the poorest has not exceeded $2 \%$ on average over the entire period since 1965 . The required rate of increase is a relatively modest 1.9 percentage points every 5 years. However, achieving a target of just $10 \%$ is likely to be extremely challenging, since for the first five-year period this rate of increase would constitute a doubling of the higher education participation rate. Although the absolute numbers of young people from the poorest population group are likely to increase as population growth continues across these countries, the long-term stagnation in the proportion of young people in this group suggests their under-representation in higher education will not be easy to overcome.

\footnotetext{
${ }^{6}$ For each of the two scenarios, we calculate the net participation rates for the respective regions as a weighted average based on the countries' respective population sizes.

7 In both these scenarios, the time dimension refers to a period of 10 years in which progressively older cohorts would have been under the age of 25 , our cut-off point for calculating net participation rates. In Figs. 6 and 7, and in our interpretation of the results, we refer to each of these periods by the mean year in which the respective age groups could have accessed higher education.

8 There could also be reasons to consider nonlinear projections. For example, one could envisage early acceleration as policymakers target the 'low-hanging fruit' of relatively easy to reach children, followed by deceleration in progress when attention then turns to the most marginalised, difficult to reach children. Conversely, progress might be slow initially as policymakers take time to implement system-wide changes, followed by acceleration as these changes bring about improvement. We adopt a linear approach recognising that while it is unlikely that countries would progress in such a neat fashion, this provides clarity and strikes a balance across alternative projections (Rose and Alcott 2015).

9 The apparent dip in participation for the richest in sub-Saharan Africa between 2000 and the latest year available is likely to be due to the proportions of over-age students who are of the official higher education age, but behind in their educational trajectory (i.e. still in primary, or secondary school) or to later starts in higher education.
} 
The more ambitious scenario, whereby the rich and poor in all countries reach around $30 \%$, ensures equal access both across and within countries in the two regions, but indicates a significant challenge even for the richest half in sub-Saharan Africa, where growth would need to increase by an average of 4.6 percentage points every 5 years (Fig. 7). This is similar to the growth required of the poorest in the South Asia under our previous, more modest scenario. Further, unprecedented growth would be needed for the poorest in sub-Saharan Africa, requiring an average increase of 6.3 percentage points for each five-year period and reaching the current rate of the richest in the region by 2030 . For South Asia, this scenario would suggest that the poorest reach the 2005 level of the richest in the region by 2025, while for sub-Saharan Africa, it would imply that the poorest should have caught up with the 2005 of the richest in the region by 2015 .

\section{Do prior education levels suggest achieving equal access in higher education can be reached?}

If higher education rates are to increase for different population groups, this requires sufficient numbers to be making it to secondary education which, in turn, requires them already to have completed primary schooling. In countries where there are wide inequalities at these levels, with low levels of access for the poorest already apparent earlier in the system, achieving equal access in higher education is likely to be extremely difficult. Such a pattern would indicate that, to achieve the desired goal for higher education, policy attention needs to take a balanced approach to equitable expansion across the system overall, with a focus on increasing access equitably in primary and secondary school in the first instance if equitable higher education access is to be achieved.

To illustrate this, we take the cohort of higher education age at the time of the survey in each country and calculate their net participation rates for primary school, secondary school and higher education. This provides an illustration of the progression of the under25 cohort through schooling and into higher education for each of the countries in our analysis (Fig. 8). We observe three patterns of wealth-driven access inequalities over the education cycle as a result of this analysis.

Firstly, in six countries, even amongst the richest, primary participation is under $80 \%$, and there are wide wealth inequalities at this level of education. These countries are all geographically clustered in West Africa, corroborating previous evidence that the region requires most progress to achieve universal primary education (UNESCO 2014, 2015). Across these six countries, the higher education participation rates are consistently under $0.5 \%$ for those in the poorest half of households, but vary significantly amongst the richest, from $1.8 \%$ in Niger to $15 \%$ in Guinea. These findings suggest that these countries will need to focus their attention on expanding access to primary schooling for the poorest, while simultaneously paying attention to promoting equity of opportunity throughout the education system.

Secondly, we identify twenty countries where secondary school access for the richest is under $80 \%$ and wealth-driven inequalities are high at this level, with less than $60 \%$ of the poorest accessing secondary education. This group includes countries in both sub-Saharan Africa and South Asia. In Malawi, for example, the gap between the rich and poor in access to secondary education reaches 35 percentage points, but access for the richest is still relatively low, at $48 \%$. This inequality persists for access to higher education: while low for both the rich and poor, the rich are over 400 times more likely to gain access. Therefore, in countries such as Malawi, the pathway to equal access to higher education requires governments to focus on extending access to secondary education for both the 


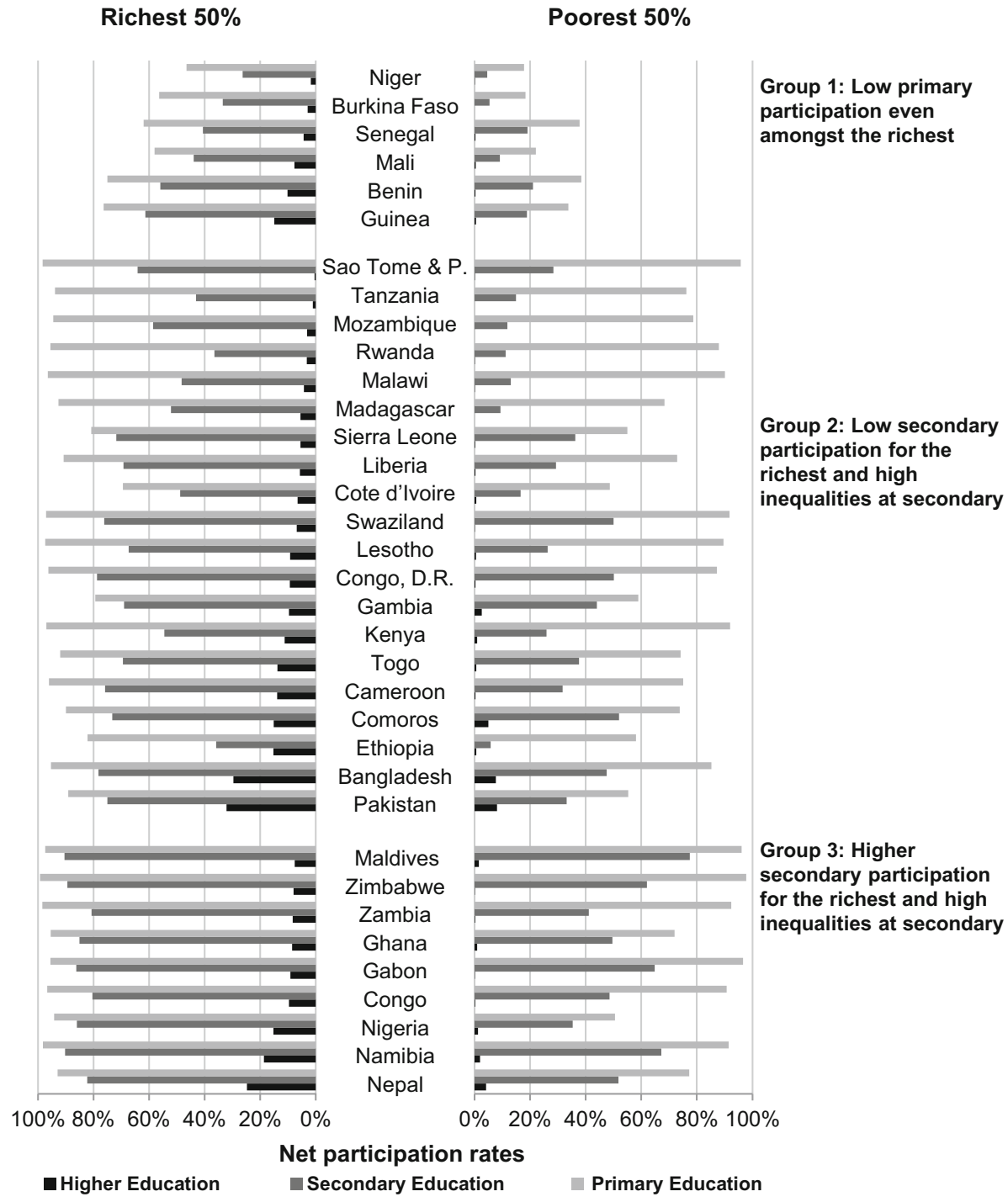

Fig. 8 Net participation rates, cohort of higher education age, by education level and country. Source: Authors' calculations based on Demographic and Health Survey data

richest and the poorest, ensuring that wealth gaps are narrowed at secondary level, and then finding ways for the poor and rich to access higher education on an equal basis.

Pakistan is also part of this group. In addition to wide inequalities at the secondary level, it also exhibits a large gap at primary level (30 percentage points). However, both the richest and the poorest have a greater chance of access to higher education compared with most other countries in the group. This would suggest if countries were to follow a similar pathway to Pakistan, they could potentially achieve similar rates of access to higher education for the richest and the poorest of those enrolled, but this would come at the 
expense of the exclusion of large proportions of the population, both poor and rich, at both primary and secondary levels.

Lastly, there are nine countries where both primary and secondary school access is high (over $80 \%$ ) for the richest, but where wealth differences at the secondary level are wide, and also wider than at primary school. For example, Zambia displays a pattern of nearuniversal access to primary education (for both rich and poor), with wealth gaps widening at secondary education (at 40 percentage points in favour of the richest) which persist into higher education, whereby the richest are more than 30 times more likely to access higher education. The higher education participation pattern is consistent across all nine countries in this group, whereby the levels of higher education participation are high for the richest, but low for the poorest. These countries will, therefore, need to focus in particular on increasing access to secondary education amongst the poorest if access to higher education is to become equal for both wealth groups.

The three distinct patterns of inequality across the different levels of education systems highlight what we believe is an important message in the context of global efforts towards the Sustainable Development Goals. The fact that inequalities between the richest and the poorest are most pronounced at higher education level does not mean that all the mechanisms by which equity can be pursued only reside at higher education level. Indeed, we argue that any progress towards narrowing the gaps at higher education requires a longterm perspective that takes into account the stages in each country's educational system where these gaps initially develop, and that addresses inequalities at primary or secondary education levels, alongside those in higher education access. This by no means a focus on primary (or secondary) education alone. Rather, we would urge that a system-wide approach be taken in the search for the interventions and actions that are most likely to lead to declining inequality between the richest and the poorest at all levels of education, which will also benefit higher education.

\section{Conclusions}

Using recent household survey data, we have shown that, across countries in South Asia and sub-Saharan Africa, the levels of attendance of higher education remain generally low, with fewer than $5 \%$ of young people gaining access in many countries. The poorest in these countries are least likely to gain access, with almost none of the poorest in some countries reaching higher education. Wealth gaps are reinforced by gender gaps, resulting in the poorest young women most likely to be excluded from higher education. Genderbased inequalities appear to be wider when overall enrolment in higher education is higher, highlighting two important issues. Firstly, in countries where only the richest have access to higher education, males and females have equal chances of reaching this level. Secondly, as participation expands, it is the young rich men who currently stand to benefit the most.

Given wide inequalities in access to higher education, our analysis further shows that proposed targets to achieve equal access by 2030 would require considerable efforts to increase enrolment for the poorest groups in particular. However, the wide inequalities that also occur in many countries at primary and at secondary levels would suggest there is an urgent need to increase education opportunities to the poorest earlier in the system if there is to be a hope of narrowing gaps in higher education by 2030. Our evidence therefore suggests that it is necessary to simultaneously tackle both unequal levels of higher 
education access and the levels of education where wealth gaps begin to manifest most strongly.

More positively with respect to gender inequalities, since greater progress has been made towards narrowing gender gaps earlier in the system on average, it may be more feasible to achieve parity for young men and women, which could mean that the global goal of equal access for men and women could be achieved. However, our analysis implies that this will be reached by maintaining access to the richest young men and women, leaving the poorest behind. Equality for all would also require structural changes that address other structural inequalities that interact with poverty (including disability for instance) for which comparable data are less readily available.

Finally, gaining a fuller understanding of gaps in access for different population groups, along with identifying whether their access is of good quality and relevant to future potential employment opportunities will require a concerted effort to provide appropriately disaggregated comparative data on a wider range of indicators on access, quality and outcomes of higher education than currently available.

Open Access This article is distributed under the terms of the Creative Commons Attribution 4.0 International License (http://creativecommons.org/licenses/by/4.0/), which permits unrestricted use, distribution, and reproduction in any medium, provided you give appropriate credit to the original author(s) and the source, provide a link to the Creative Commons license, and indicate if changes were made.

\section{References}

Altbach, P. G., Reisberg, L., \& Rumbley, L. E. (2009). Trends in global higher education: Tracking an academic revolution. A report prepared for the UNESCO 2009 world conference on higher education. http://www.uis.unesco.org/Library/Documents/trends-global-higher-education-2009-world-conferenceen.pdf. Accessed October 16, 2015.

Aluede, O., Idogho, P. O., \& Imonikhe, J. S. (2012, June). Increasing access to university education in Nigeria: present challenges and suggestions for the future. In The African Symposium (Vol. 12, No. 1, pp. 3-13).

Bloom, D. E., Canning, D., Chan, K., \& Luca, D. L. (2014). Higher education and economic growth in Africa. International Journal of African Higher Education, 1(1), 22-57.

Carnoy, M., Loyalka, P., Dobryakova, M., Dossani, R., Froumin, I., Kuhns, K., et al. (2013). University expansion in a changing global economy: Triumph of the BRICs?. Stanford: Stanford University Press.

Chien, C., \& Montjourides, P. (2016). Global trends in access to post-secondary education. In A. MountfordZimdars \& N. Harrison (Eds.), Access to higher education: Theoretical perspectives and contemporary challenges. Abingdon: Routledge.

Colclough, C., Kingdon, G., \& Patrinos, H. A. (2009). The pattern of returns to education and its implications. Policy Brief 4. Cambridge: Research Consortium on Educational Outcomes and Poverty (RECOUP).

DHS implementing partners and ICF International. (1988-2015). Demographic and Health Surveys. (various datasets 2007-2014). Calverton, Maryland: ICF International.

Fasih, T., Kingdon, G., Patrinos, H. A., Sakellariou, C., \& Soderbom, M. (2012). Heterogeneous returns to education in the labor market. Policy Research Working Paper. The World Bank.

Filmer, D., \& Pritchett, L. H. (2001). Estimating wealth effects without expenditure Data-Or tears: An application to educational enrollments in states of India. Demography, 38(1), 115-132.

Jamshidi, L., Arasteh, H., NavehEbrahim, A., Zeinabadi, H., \& Rasmussen, P. D. (2012). Developmental patterns of privatization in higher education: A comparative study. Higher Education, 64(6), 789-803.

Jerrim, J., \& Vignoles, A. (2015). University access for disadvantaged children: a comparison across countries. Higher Education, 70(6), 903-921.

Keeling, R. (2006). The Bologna Process and the Lisbon Research Agenda: The European Commission's expanding role in higher education discourse. European Journal of Education, 41(2), 203-223.

Klasen, S., \& Lamanna, F. (2009). The impact of gender inequality in education and employment on economic growth: new evidence for a panel of countries. Feminist Economics, 15(3), 91-132. 
Marginson, S., \& Van Der Wende, M. (2007). Globalisation and higher education. OECD Education Working Papers, 8. OECD Publishing.

McCowan, T. (2007). Expansion without equity: An analysis of current policy on access to higher education in Brazil. Higher Education, 53(5), 579-598.

McCowan, T. (2015). Three dimensions of equity of access to higher education. Compare: A Journal of Comparative and International Education. doi:10.1080/03057925.2015.1043237.

McMahon, W. W. (2009). Higher learning, greater good: The private and social benefits of higher education. Baltimore: Johns Hopkins University Press.

Moretti, E. (2004). Estimating the social return to higher education: evidence from longitudinal and repeated cross-sectional data. Journal of Econometrics, 121(1), 175-212.

OECD. (2014). Education at a Glance 2014: OECD Indicators. Paris: OECD Publishing. doi:10.1787/eag2014-en.

OECD. (2015). Online Education Database. OECD Publishing. http://www.oecd.org/education/database. htm. Accessed January-September 2015.

Ogunmuyiwa, M. S., \& Okuneye, B. A. (2015). Does tertiary enrolment cause growth in Nigeria? A vector auto regression mechanism. International Journal of Economics and Finance, 7(7), 131-137.

Oketch, M., McCowan, T., \& Schendel, R. (2014). The impact of tertiary education on development: A rigorous literature review. EPPI-Centre Report 2205. Department for International Development https://eppi.ioe.ac.uk/cms/LinkClick.aspx?fileticket=P0RTfd_qWFo\%3D\&tabid=3437. Accessed September 29, 2015.

Rose, P., \& Alcott, B. (2015). How can education systems become equitable by 2030? DFID think piecesLearning and equity. Report prepared for UK Department for International Development Health and Education Advice and Resource Team (HEART). Oxford, UK.

Rutstein, S. O., \& Johnson, K. (2004). The DHS wealth index. DHS Comparative Reports No. 6. ORC Macro, Calverton, Maryland USA. https://dhsprogram.com/pubs/pdf/CR6/CR6.pdf. Accessed October 23, 2014

Salmi, J., \& Bassett, R. M. (2014). The equity imperative in tertiary education: Promoting fairness and efficiency. International Review of Education, 60(3), 361-377.

Schofer, E., \& Meyer, J. W. (2005). The worldwide expansion of higher education in the twentieth century. American Sociological Review, 70(6), 898-920.

Sumner, A. (2012). Where do the World's Poor Live? A New Update. IDS Working Paper 39. IDS. Available online: http://www.ids.ac.uk/files/dmfile/Wp393.pdf.

Susanti, D. (2011). Privatisation and marketisation of higher education in Indonesia: the challenge for equal access and academic values. Higher Education, 61(2), 209-218.

Teal, F. (2011). Higher education and economic development in Africa: A review of channels and interactions. Journal of African Economies, 20(suppl. 3), iii50-iii79.

Technical Advisory Group (2015). Technical Advisory Group Proposal: Thematic Indicators to Monitor the Post-2015 Education Agenda. World Education Forum 2015 Report ED/WEF2015/REF/10. http:// www.uis.unesco.org/Education/Documents/tag-proposed-thematic-indicators-post2015-education-agenda. pdf. Accessed October 20, 2015.

Teferra, D., \& Altbachl, P. G. (2004). African higher education: Challenges for the 21st century. Higher Education, 47(1), 21-50.

The United Nations (UN). (1948). Universal Declaration of Human Rights.

The United Nations (UN). (1976). International Covenant on Economic, Social and Cultural Rights.

The United Nations (UN). (2015). Transforming our world: the 2030 Agenda for Sustainable Development. Resolution adopted by the General Assembly on 25 September 2015. Seventieth session. http://www. un.org/ga/search/view_doc.asp?symbol=A/RES/70/1\&Lang=E. Accessed October 21, 2015.

Tilak, J. B. (2014). Private higher education in India. Economic and Political Weekly, 49(40), 32-38.

Traynor, A., \& Raykov, T. (2013). Household possessions indices as wealth measures: a validity evaluation. Comparative Education Review, 57(4), 662-688.

Trow, M. (1973). Problems in the transition from elite to mass higher education. Carnegie Commission on Higher Education Commission Reports. http://files.eric.ed.gov/fulltext/ED091983.pdf. Accessed September 24, 2015.

Trow, M. (2007). Reflections on the transition from elite to mass to universal access forms and phases of higher education in modern societies since WWII. In J. F. Forest \& P. G. Altbach (Eds.), International handbook of higher education (pp. 243-280). New York: Springer.

UNESCO. (2014). Education for All Global Monitoring Report. Teaching and Learning: Quality for All. Education for All Global Monitoring Report 2014. Paris: UNESCO.

UNESCO. (2015) Education for All 2000-2015: Achievements and Challenges. Education for All Global Monitoring Report 2015. UNESCO: Paris, France. 
UNESCO Institute for Statistics. (2009). Education Indicators: Technical guidelines. http://www.uis.unesco. org/Library/Documents/eiguide09-en.pdf. Accessed June 3, 2015.

UNESCO Institute for Statistics. (2011). ISCED 2011 Operational Manual. http://www.uis.unesco.org/ Education/Documents/isced-2011-operational-manual.pdf. Accessed May 28, 2015.

UNESCO Institute for Statistics. (2014). Higher Education In Asia: Expanding Out, Expanding Up: The rise of graduate education and university research. http://www.uis.unesco.org/Library/Documents/highereducation-asia-graduate-university-research-2014-en.pdf. Accessed January 18, 2015.

UNESCO Institute for Statistics. (2015). Data Centre-Theme: Education. http://data.uis.unesco.org/. Accessed January-September 2015.

World Bank. (2016). Data. Sub-Saharan Africa (developing only). http://data.worldbank.org/region/SSA. 